\title{
Ageing effect on the creep performance of simulated weld HAZ for the steels X20 and P91
}

\author{
Fevzi Kafexhiu ${ }^{1, *}$, Bojan Podgornik ${ }^{1}$, and Franc Vodopivec $^{1}$ \\ ${ }^{1}$ Institute of metals and technology, Lepi pot 11, 1000 Ljubljana, Slovenia
}

\begin{abstract}
Changes in size- and spatial distribution of precipitates and their effect on stationary creep rate of two grades of creep-resistant $9-12 \%$ $\mathrm{Cr}$ steels, $\mathrm{X} 20$ and P91, as a function of ageing at two different conditions were investigated. Ageing of both steels was performed at $650^{\circ} \mathrm{C}$ lasting up to 2 years and at $750^{\circ} \mathrm{C}$ lasting up to 6 months. Prior to the ageing, simulation of two weld heat-affected zone HAZ regions, i.e., coarsegrained microstructure $(\gamma)$, and grain-refined microstructure $(\alpha+\gamma)$ was performed. Accelerated creep tests at $580^{\circ} \mathrm{C}$ and $170 \mathrm{MPa}$, lasting up to 100 hours were performed on the above microstructures prior to- and after the ageing. In addition, optical and SEM imaging were performed on metallographic specimens, followed by image analysis. Deterioration of the creep performance show a proportional behaviour with the precipitate coarsening, which is more pronounced after the ageing at $750^{\circ} \mathrm{C}$. Comparatively, the increase of the stationary creep rate after the ageing at $650^{\circ} \mathrm{C}$ was more pronounced in the steel $\mathrm{X} 20$ than in the P91. In both steels and both tempering temperatures, the most troublesome region with respect to the creep behaviour was observed to be the simulated intercritical $(\alpha+\gamma)$ HAZ microstructure.
\end{abstract}

\section{Introduction}

Studies on creep resistance of modified $9-12 \% \mathrm{Cr}$ steels have been largely focused on the rupture strength of the parent metal. Much less attention has been given to the behaviour of welded joints. However, long-term experience of creep exposed welded structures has shown that the heat affected zone (HAZ), a narrow zone of parent metal adjacent to the weld fusion line altered by the weld thermal cycle, in respect to the creep strength, is often regarded as the weakest link in welded constructions [1-3].

Particles with different size, spacing, and distribution are present in the HAZ after a multilayer welding. Studies [4-6] have shown that there is a correlation between the size, spacing, and distribution of precipitates on the one hand and creep properties on the other.

Therefore, the aim of the present work was to investigate the changes in the number density $(n)$, size $(d)$, surface share $(f)$, and mutual spacing $(\lambda)$ of particles in the parent metal $(\alpha)$ and two regions of the HAZ, $\alpha+\gamma$ and $\gamma$ of two $9-12 \%$ Cr steel grades, the X20 and the P91, as a function of ageing, and the effect of these changes on the stationary creep rate $(\dot{\varepsilon})$.

* Corresponding author: fevzi.kafexhiu@imt.si 


\section{Materials and Methods}

Two creep-resistant 9-12\% Cr steels, the DIN X20CrMoV121 (X20 hereafter) and the DIN $\mathrm{X} 10 \mathrm{CrMoVNb} 91$ (P91 hereafter) with the chemical composition given in [7] were the subject of this investigation.

Heat treatment of the parent metal $(\alpha)$ of both steels was carried out to simulate two HAZ regions, i.e., the inter-critical $(\alpha+\gamma)$ and the coarse-grained $(\gamma)$. The $\alpha+\gamma$ microstructure was obtained by keeping both steels at $845 \pm 5^{\circ} \mathrm{C}$ (Ac1 $<T<\mathrm{Ac} 3$ ) for 60 minutes. The $\gamma$ microstructure was obtained by keeping both steels at $1000^{\circ} \mathrm{C}(>\mathrm{Ac} 3)$ for 30 minutes. The $\alpha, \alpha+\gamma$, and $\gamma$ have the microstructure of tempered martensite, with a grain size gradient going from the fine-grained $\alpha+\gamma$ (partial austenitization) to the normal-grained $\alpha$ (the parent metal) to coarse-grained $\gamma$ (full austenitization).

An additional heat treatment, was performed to induce the changes of size, distribution and mutual spacing of carbide/nitride particles, and consequently the creep properties of the studied steels. It consisted of ageing of all the three microstructures $(\alpha, \alpha+\gamma$, and $\gamma)$ of the both X20 and P91 steels for $4320 \mathrm{~h}\left(6\right.$ months) at $750^{\circ} \mathrm{C}$ and $17520 \mathrm{~h}(2$ years $)$ at $650^{\circ} \mathrm{C}$.

Accelerated creep tests lasting up to 100 hours were performed prior to- and after the ageing. Tests were performed using in-house designed creep test machines with dead weight at a stress of $170 \mathrm{MPa}$ and the constant temperature of $580^{\circ} \mathrm{C}$.

Metallographic samples were prepared from threaded ends of crept specimens and the SEM imaging was performed at the 10k magnification. On such images (Fig. 1 and Fig. 3), automatic image analysis was carried out using the FIJI software [8] with ,3D Object Counter" plugin [9]. Along with surface area, the plugin provides centroid coordinates of particles, making it possible to find the nearest neighbour $\left(\lambda_{i}\right)$ for each analysed particle by applying an algorithm based on the Equation 1.

$$
\lambda_{i}=\min _{i=1}^{n} \sqrt{\left(x_{i}-x_{j}\right)^{2}+\left(y_{i}-y_{j}\right)^{2}}
$$

with $n$ - number of analysed particles, $\lambda_{i}$ - distance between a particle with centroid coordinates $\left(x_{i}, y_{i}\right)$ and its nearest neighbour $\left(x_{j}, y_{j}\right)$. The algorithm iterates $j$ for the first particle $(i=1)$ until the condition of the smallest $\lambda_{1}$ value is met, and then with the same iteration searches the nearest neighbour for the second particle $(i=2)$, and so on.

\section{Results}

SE images showing the microstructure evolution of the parent metal $(\alpha)$ and the simulated HAZ regions $(\alpha+\gamma$ and $\gamma)$ for the steel X20 as a function of ageing at two different temperatures and durations are presented in the Fig. 1. It shows how the 6 months of ageing at $750^{\circ} \mathrm{C}$ has a greater effect on particles' coarsening than the ageing for 2 years at $650^{\circ} \mathrm{C}$.

For the parent metal $(\alpha)$, visual changes after the ageing for 2 years at $650^{\circ} \mathrm{C}$ are minor, whereas for the inter-critical $(\alpha+\gamma)$ and coarse-grained $(\gamma)$ HAZ, the changes are quite pronounced, i.e., much coarser particles with random distribution as compared to the initial state, having fine particles, mainly located along grain and sub-grain boundaries. After the 6 months of ageing at $750^{\circ} \mathrm{C}$, particles with random distribution have grown coarser than 1 $\mu \mathrm{m}$ in equivalent diameter, and their mutual spacing is much larger as compared to the initial state.

Along with the creep rate $(\dot{\varepsilon})$, the Fig. 2 and Fig. 4 show the results of quantitative analysis performed on the SE images from the Fig. 1 and Fig. 3 respectively, including number density of particles $(n)$, surface share of particles $(f)$, particles' equivalent diameter $(d)$, and mutual spacing $(\lambda)$, all as a function of ageing time and temperature. 

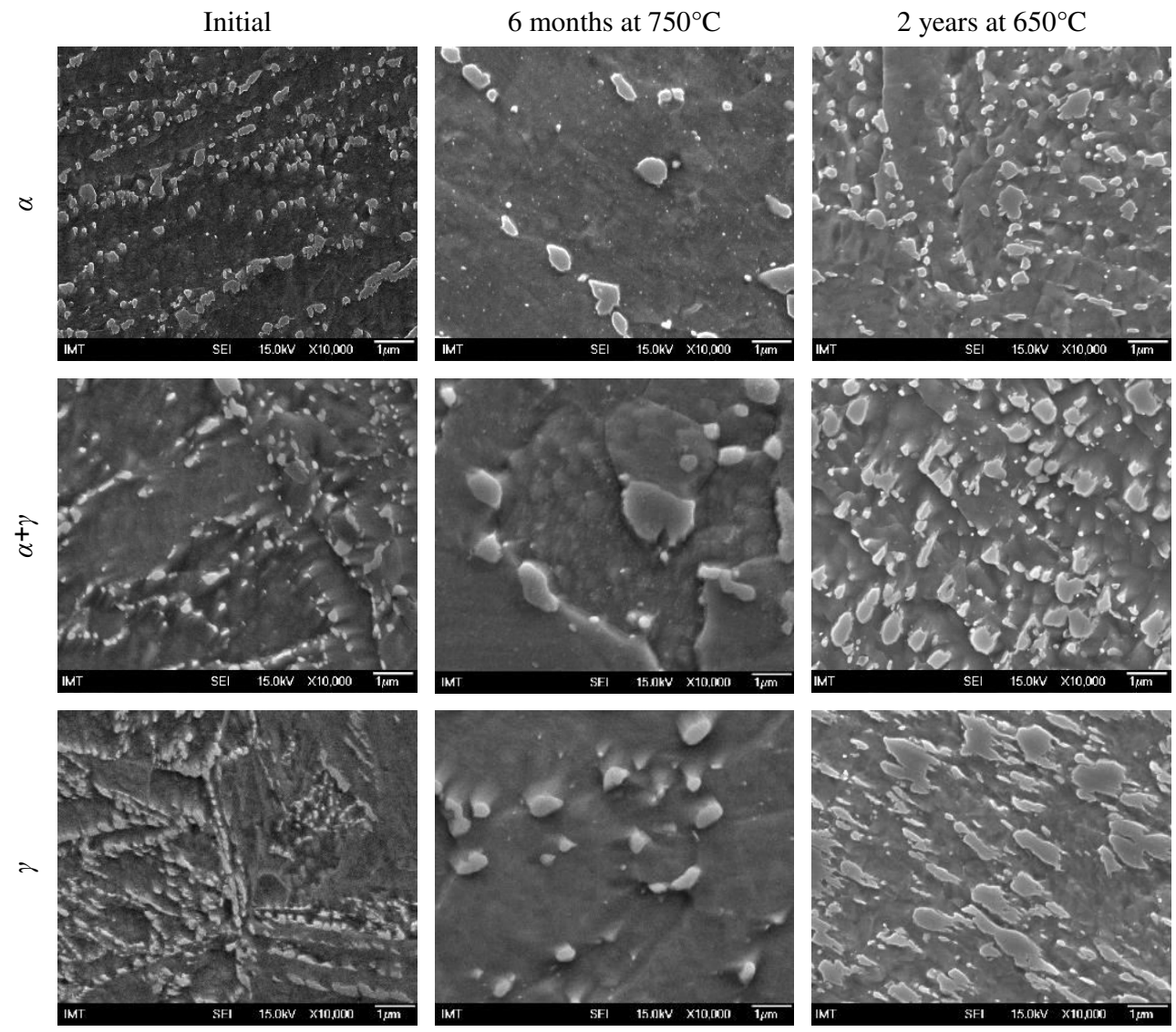

Fig. 1. SE images showing the evolution of the simulated HAZ regions $(\alpha, \alpha+\gamma$, and $\gamma)$ for the steel $\mathrm{X} 20$ as a function of ageing.

The plot in the Fig. 2 (a) shows a linear decrease of the number density $(n)$ and surface share $(f)$ of particles as a function of ageing for the parent metal $(\alpha)$ of the steel X20. A nonlinear dependency of the change in the $n$ and $f$ as a function of ageing at two different conditions is expressed by the $\alpha$ and $\alpha+\gamma$ microstructures, except for the $\gamma$ aged at $650^{\circ} \mathrm{C}$, where the changes in the $n$ and $f$ are inversely proportional. This could be explained by the fact that the number of coarse precipitates in the $\gamma$ is higher than in the $\alpha$ and $\alpha+\gamma$ microstructures (see Fig. 1), thus contributing to a higher $f$ even for the lower $n$. Note that by ageing for 2 years at $650^{\circ} \mathrm{C}$, the $f$ of the $\alpha+\gamma$ and $\gamma$ increases strongly, i.e., from less than $10 \%$ at the initial state to $25 \%$ and $31 \%$, respectively.

The plot in the Fig. 2 (b) represents a correlation between the creep rate (c) on the one hand, and the particles size $(d)$ and spacing $(\lambda)$ on the other as a function of ageing for the steel X20. Clearly, the $d$ and $\lambda$ show a mutual dependence. The most pronounced change is spotted in the $\lambda$ for the $\alpha+\gamma$ and $\gamma$ microstructures after ageing at $750^{\circ} \mathrm{C}$.

The increase of the $\dot{\varepsilon}$ after 6 month of ageing the steel $\mathrm{X} 20$ at $750^{\circ} \mathrm{C}$ is higher as compared to the one aged for 2 years at $650^{\circ} \mathrm{C}$. The increase of the $\dot{\varepsilon}$ for specimens aged at $650^{\circ} \mathrm{C}$ follows an identical slope for all three microstructures, with the $\gamma$ showing the lowest $\dot{\varepsilon}$, while the $\alpha+\gamma$ the highest. After ageing at $750^{\circ} \mathrm{C}$, however, the increase in the $\dot{\varepsilon}$ is the highest for the $\gamma$ and the lowest for the $\alpha$ microstructure. 


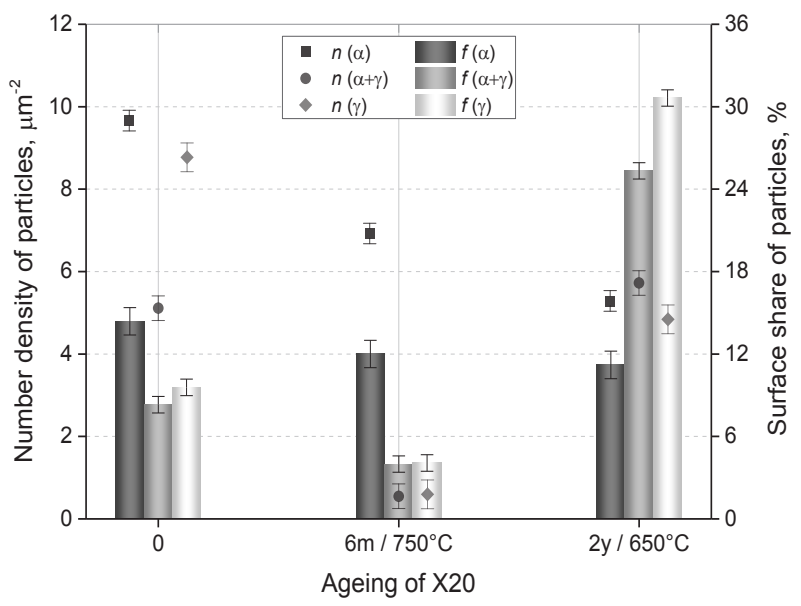

(a)

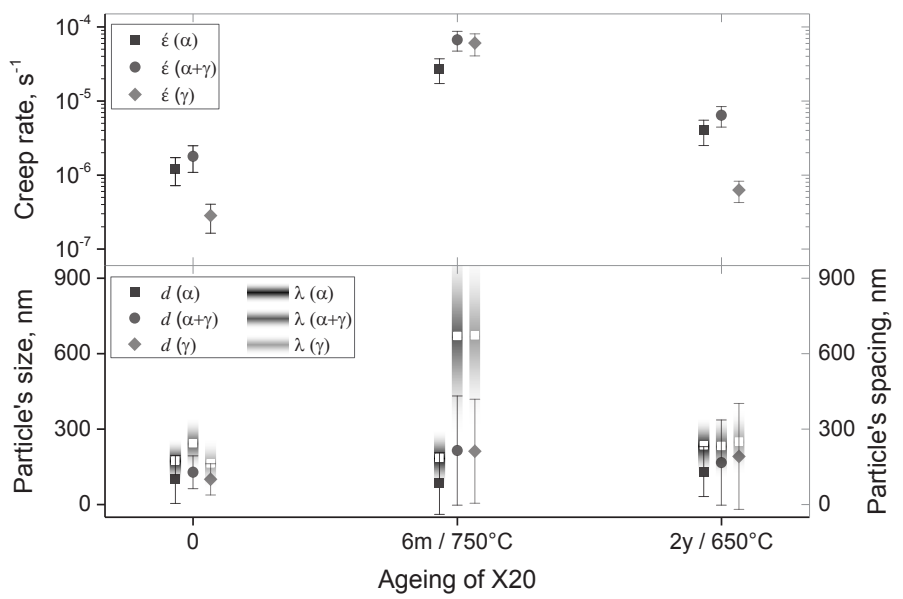

(b)

Fig. 2. Particles' statistics (a) and the creep rate (b) of the simulated HAZ regions $(\alpha, \alpha+\gamma$, and $\gamma)$ for the steel X20 as a function of ageing.

The visual discrepancy between the SE image of $\alpha$ microstructure of the steel X20 aged for 6 month at $750^{\circ} \mathrm{C}$ shown in Fig. 1, and the respective values of the $d$ and $\lambda$ shown in the Fig. 2, appears as a result of very fine MX particles that are barely visible to the naked eye but detectable by the automatic image analysis.

SE images showing the microstructure evolution of the steel P91 as a function of ageing at two different conditions are given in Fig. 3. Similarly to the steel X20, the ageing for 6 months at $750^{\circ} \mathrm{C}$ has a greater effect on particle's coarsening than the ageing for 2 years at $650^{\circ} \mathrm{C}$. For the parent metal $(\alpha)$ and the inter-critical $(\alpha+\gamma)$ HAZ microstructure, the changes after 2 years of ageing at $650^{\circ} \mathrm{C}$ are minor, whereas for the coarse-grained $(\gamma) \mathrm{HAZ}$ microstructure, the changes are quite pronounced. At the initial state, carbide/nitride particles are not fully precipitated, whereas after the ageing, particles' size and distribution are comparable to those in $\alpha$ and $\alpha+\gamma$. The ageing at a higher temperature, i.e., $750^{\circ} \mathrm{C}$ for 6 months, resulted in coarser randomly distributed particles with a much larger mutual spacing as compared to the initial state. In addition, similarly to the steel X20, very fine particles with a high number density are present in the $\alpha$ microstructure along with coarse $\mathrm{M}_{23} \mathrm{C}_{6}$ precipitates. However, this is not the case in the $\alpha+\gamma$ and $\gamma$ microstructures. 

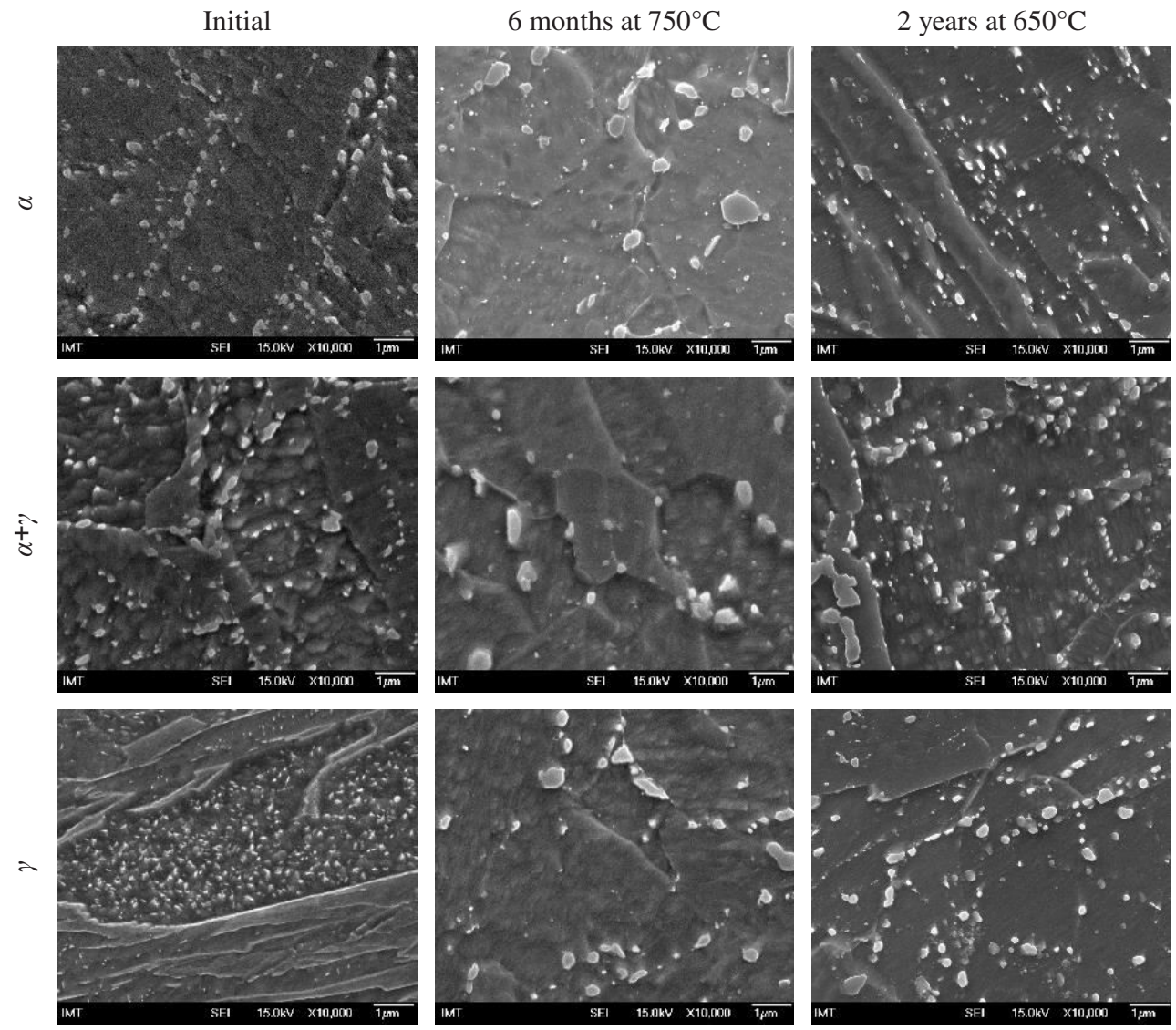

Fig. 3. SE images showing the evolution of simulated HAZ regions $(\alpha, \alpha+\gamma$, and $\gamma)$ for the steel P91 as a function of ageing.

Detailed particles statistics for the steel P91 is given in the Fig. 4 (a), indicating a proportional decrease in the $n$ and $f$ of as a function of ageing at $750^{\circ} \mathrm{C}$ for all three microstructures $(\alpha, \alpha+\gamma$, and $\gamma)$. At this state, the $f$ values are virtually equalized. In the $\alpha+\gamma$ and $\gamma$ of the steel P91, the $n$ increases with ageing at $650^{\circ} \mathrm{C}$ while the $f$ is virtually constant. However, in the case of the $\alpha$, both the $n$ and $f$ decrease with the ageing.

From the plot in the Fig. 4 (b), the $\varepsilon$ increases with the ageing temperature. For specimens aged at $650^{\circ} \mathrm{C}$, the $\varepsilon$ of the $\alpha+\gamma$ microstructure remains virtually constant, while the $\dot{\varepsilon}$ of the $\gamma$ increases for about an order of magnitude. Surprisingly, the $\dot{\varepsilon}$ of the $\alpha$ microstructure decreases with ageing. The increase slope of $\dot{\varepsilon}$ as a function of ageing at $750^{\circ} \mathrm{C}$ is the flattest for the $\alpha$, and the steepest for the $\gamma$ microstructure.

Changes in the $d$ and $\lambda$ from the plot of the Fig. 4 (b), indicate a clear mutual correlation and the dependence of the creep rate $(\dot{\varepsilon})$ on the both $d$ and $\lambda$.

Similarly to the steel X20, there is a visual discrepancy between the SE image of the $\alpha$ microstructure aged for 6 month at $750^{\circ} \mathrm{C}$ shown in the Fig. 3, and the respective values of the $d$ and $\lambda$ shown in the Fig. 4 (b). This is due to very fine MX particles that are barely visible to the naked eye but detectable by the automatic image analysis. 


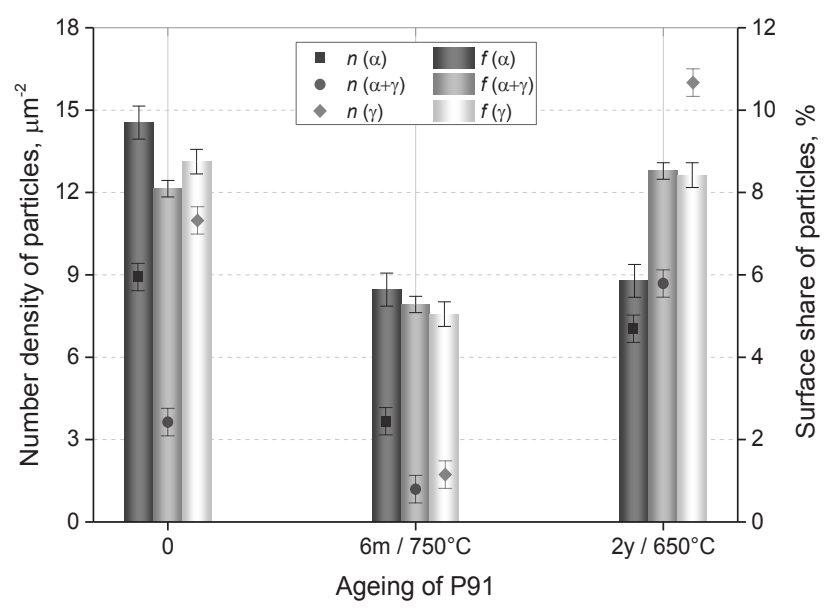

(a)

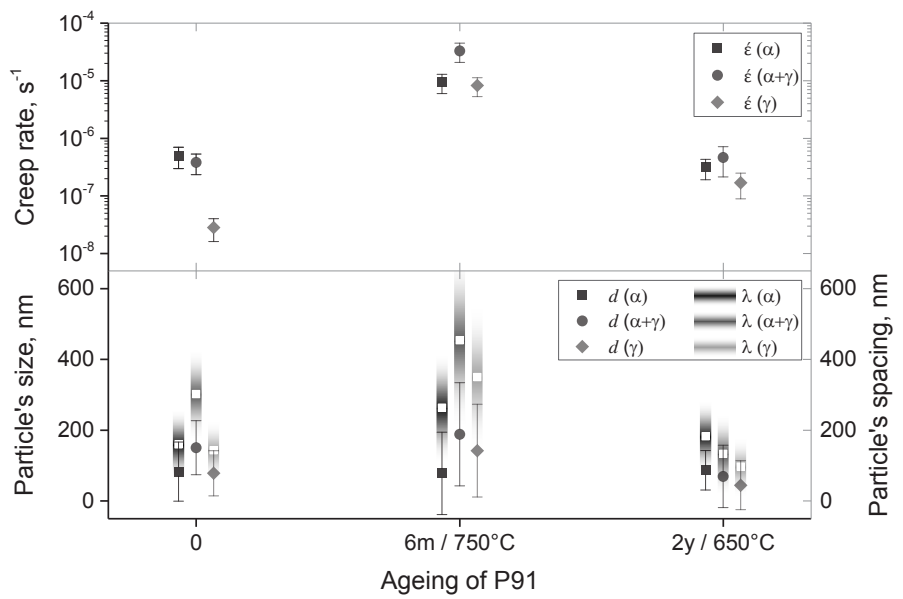

(b)

Fig. 4. Particles' statistics (a) and the creep rate (b) of the simulated HAZ regions $(\alpha, \alpha+\gamma$, and $\gamma)$ for the steel P91 as a function of ageing.

\section{Discussion}

The dependence $\dot{\varepsilon}=f(d, \lambda)$ has been treated in a series of articles (10-12), where the values of the $d$ and $\lambda$ are obtained by the particles' coarsening kinetics (13-17) and the mean interparticle distance theory (18), respectively. In this study, by contrast, the size $d$ represents the equivalent diameter calculated from the surface area of each analysed particle. The latter was obtained by automatic analysis of SE images in the Fig. 1 and Fig. 3.

A clearer picture of the relationship between the $\dot{\varepsilon}, d$, and $\lambda$ is shown in the Fig. 5 in the form $\dot{\varepsilon}=f(\lambda-d)$. The $\lambda-d$ parameter represents the average distance measured on the outer surface of precipitates with the average equivalent diameter $d$, whereas $\lambda$ is the average distance between the centroids of the precipitates.

From the Fig. 5 (a) it is evident that for specimens aged at $650^{\circ} \mathrm{C}$, the $\dot{\varepsilon}$ increases while the $\lambda-d$ decreases with ageing, which is true for the $\alpha+\gamma$ and $\gamma$ HAZ microstructures of both steels. For the parent metal $(\alpha)$, the $\lambda-d$ parameter increases with ageing at $650^{\circ} \mathrm{C}$ for both steels, whereas the $\varepsilon$ increases for the steel X20 but decreases for the P91. 


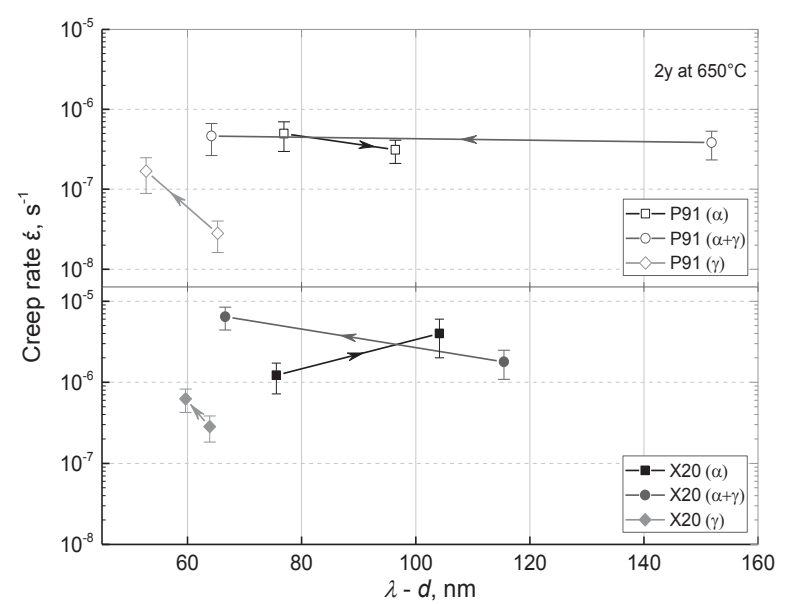

(a)

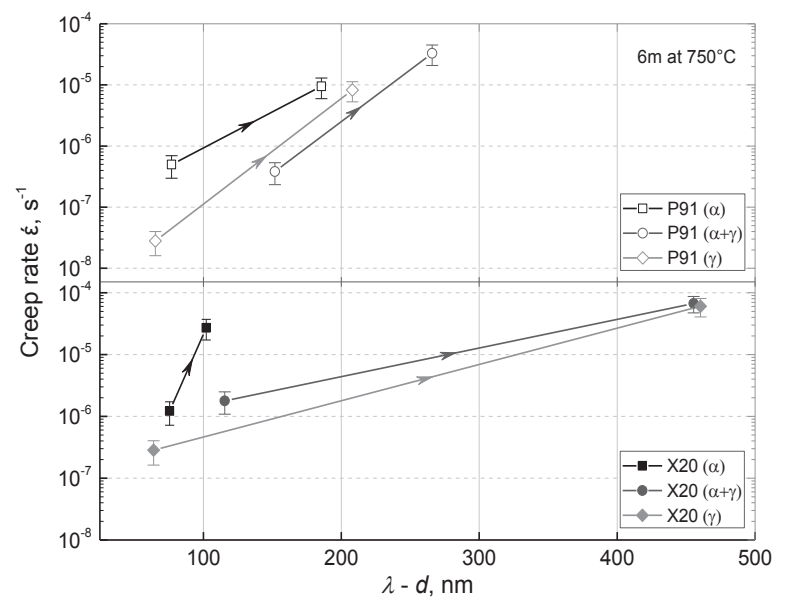

(b)

Fig. 5. Creep rate vs. the $\lambda-d$ for the $\alpha, \alpha+\gamma$, and $\gamma$ of the steels X20 and P91 aged for (a) 2 years at $650^{\circ} \mathrm{C}$ and (b) 6 months at $750^{\circ} \mathrm{C}$. Arrows indicate the direction initial state $\rightarrow$ aged state.

The dependence $\varepsilon^{\prime}=f(\lambda-d)$ as a function of ageing at $750^{\circ} \mathrm{C}$ is shown in the Fig. 5 (b). In contrast to specimens aged at $650^{\circ} \mathrm{C}$, for both steels, $\dot{\varepsilon}$ was found to increase with the $\lambda$ $d$ parameter, i.e., with ageing.

For the steel X20, there is a huge difference in the $\lambda-d$ parameter between the parent metal $(\alpha)$ and two HAZ microstructures $(\alpha+\gamma$ and $\gamma)$ after the ageing at $750^{\circ} \mathrm{C}$. However, the difference in the $\varepsilon$ is not so drastic, although the two HAZ microstructures show slightly higher $\dot{\varepsilon}$ as compared to the parent metal. It can be also noted that at the initial state, the $\gamma$ microstructure has the lowest $\dot{\varepsilon}$ as compared to the $\alpha$ and $\alpha+\gamma$, which show a similar $\dot{\varepsilon}$.

For the steel P91, the relationship $\dot{\varepsilon}=f(\lambda-d)$ shows a similar slope for all three microstructures $(\alpha, \alpha+\gamma$, and $\gamma)$, however the particular $\dot{\varepsilon}$ and $\lambda-d$ values are different. At the initial state, the $\alpha$ and $\alpha+\gamma$ microstructures show a comparable $\varepsilon$, while the $\gamma$ shows an order of magnitude lower $\varepsilon$ and the lowest $\lambda-d$. After the ageing, the $\varepsilon$ gets similar for the $\alpha$ and $\gamma$ microstructures and half an order of magnitude lower than for the $\alpha+\gamma$. The latter also shows the highest values of the $\lambda-d$ parameter prior to- and after the ageing.

In general, results show that the deterioration in creep resistance (increase of creep rate) is for both steels faster for the higher ageing temperature, i.e., $750^{\circ} \mathrm{C}$. Results also reveal 
that the creep rate increase shows no dependence on the size and spacing of precipitates by ageing at $650^{\circ} \mathrm{C}$, while ageing at $750^{\circ} \mathrm{C}$ has a proportional effect on both the creep rate and precipitate coarsening (size and spacing). This means that for specimens aged at $650^{\circ} \mathrm{C}$ for 2 years, light should be shed in different deteriorating mechanisms, which e.g., for the steel P91 could be the precipitation of Laves- and Z-phase.

\section{Conclusion}

Based on the statistical analysis of precipitates, there is a good correlation between number density $(n)$ and surface share $(f)$ on the one hand, and the size (equivalent diameter) $(d)$ and spacing $(\lambda)$ of precipitates, on the other.

In general, the deterioration of creep resistance (increase of the creep rate) shows no dependence on the size and spacing of precipitates by ageing at $650^{\circ} \mathrm{C}$, while the ageing at $750^{\circ} \mathrm{C}$ has a proportional effect on both the creep rate and precipitate coarsening (size and spacing). For the steel P91, the dependence of the creep rate on the precipitates' size and spacing is similar for all three microstructures $(\alpha, \alpha+\gamma, \gamma)$, whereas in the case of the steel $\mathrm{X} 20$, the dependence for the parent metal $(\alpha)$ is stronger than that of the simulated $\alpha+\gamma$ and $\gamma$ HAZ microstructures.

\section{References}

1. F. Abe, T.U. Kern, R. Viswanathan, Creep-resistant steels (Woodhead Publishing, CRC Press, Cambridge, UK, 2008)

2. P. Mayr, T.A. Palmer, J.W. Elmer, H. Cerjak, Adv. Mater. Res. 15-17, 1014-1019 (2007)

3. P. Parameswaran, K. Laha, Procedia Eng. 55, 438-442 (2013)

4. J. Hald, Int. J. Pres. Ves. Pip. 85, 30-37 (2008)

5. D.A. Skobir, M. Jenko, F. Vodopivec, R. Celin, Mat. Tech. 45, 6, 555-559 (2011)

6. F. Vodopivec, M. Jenko, R. Celin, B. Žužek, D.A. Skobir, Mat. Tech., 45, 2, 139-143 (2011)

7. F. Kafexhiu, B. Podgornik, F. Vodopivec, Metalurgija 56, 3-4, 353-356 (2017)

8. J. Schindelin, I. Arganda-Carreras, E. Frise, et al., Nat. Methods 9, 676-682 (2012)

9. S. Bolte, F.P. Cordelières, J. Microsc. 224, 213-232 (2006)

10. E. Hornbogen in: W. Dahl, W.Pitch, Festigkeits- und Bruchverhalten bei höheren Temperaturen, 31-52 (Verlag Stahleisen GmbH, Düsseldorf, 1980)

11. F. Vodopivec, F. Kafexhiu, B. Žužek, Steel Res. Int. 88, 6 (2017)

12. F. Vodopivec, F. Kafexhiu, B. Žužek, B. Podgornik, Steel Res. Int. 88, 3 (2017)

13. I.M. Lifshitz, V.V. Slyozov, J. Phys. Chem. Solids 19, 35-50 (1961)

14. C. Wagner, Z. Electrochem., 65, 581-591 (1961)

15. F. Vodopivec, F. Kafexhiu, B. Žužek, Steel Res. Int. 86, 278-283 (2015)

16. F. Vodopivec, D. Steiner-Petrovič, B. Žužek, M. Jenko, Steel Res. Int. 84, 1110-1114 (2013)

17. J. Hald, L. Korcakova, ISIJ Int. 43, 420-427 (2003)

18. P. Hertz, Math. Ann. 67, 387-398 (1909) 